\title{
Utilization of Intravascular Ultrasound to Assess Vascular Invasion in Pancreatic Cancer Post Chemoradiation Therapy
}

\author{
Feghali $A^{*}$, Amankwah K, Goldenberg A, Karmel M and Mendenhall C
}

State University of New York Upstate Medical University, Syracuse, New York, USA

\begin{abstract}
Surgery continues to be the principal treatment for patients with resectable pancreatic cancer. Computer tomography $(\mathrm{CT})$ is the primary modality used to assess the tumor and its involvement with neighboring vasculature to determine resectability. Regrettably, CT as well as many other non-invasive imaging modalities cannot continuously differentiate between vascular invasion and compression. Intravascular ultrasound represents a modality that can be used as an adjunct to delineate tumour vascular involvement. This case represents a first report of IVUS being used post chemoradiation therapy to determine a patient's candidacy for resection.
\end{abstract}

Keywords: Pancreatic cancer; Intravascular ultrasounds (IVUS); Tumor invasion; Chemoradiation; Portal vein, Superior mesenteric vein $(\mathrm{SMV})$

\section{Introduction}

Pancreatic adenocarcinoma is one of the deadliest cancers known. It is the sixth most common cancer and fourth most common cause of cancer deaths [1]. Only a small percentage of people present with cancer isolated to the pancreas, leaving $80-90 \%$ of people with unresectable tumors on initial discovery $[1,2]$. While surgical resection remains the mainstay of curative therapy for pancreatic cancer, invasive tumor involving the surrounding vasculature is often a contraindication to surgery. Unfortunately, many noninvasive imaging modalities do not have sufficient resolution to distinguish between vascular invasion and compression, which is often the most important determinant whether the patient should seek a curative surgical procedure. The weight of this decision is further compounded by the fact that surgery has significant mortality and morbidity, and surgical discovery of posterior and lateral wall vascular invasion is only possible when such procedures are well advanced.

The conventional method for assessing pancreatic cancer and vascular involvement has been utilization of computed tomography (CT), which is $91 \%$ sensitive and $85 \%$ specific $[1,3]$. In most situations these numbers would suggest that CT is a very good test. But, in cases where initially vascular invasion was thought to be possible and neoadjuctive chemotherapy and/or radiation have been employed the diagnosis becomes much more difficult. Tumors may contract and mass effect on the vessel may resolve, but invasion may still be present. For these reasons definitive diagnosis of vascular invasion in a treated patient can be challenging. Other imaging modalities have been used as adjuncts to better define vascular association [1,4-6].

One such modality is intravascular ultrasound, or IVUS. This device has been available for decades and has sub-millimeter resolution. It provides a two-dimensional image from inside the lumen of the vessel. IVUS has been most commonly employed in assessing atherosclerotic plaque in coronary and peripheral arteries, though it is gaining favor in other areas. A few studies with small patient populations have established its use as an adjunct to evaluate vascular involvement in pancreatic cancer preoperative and intraoperative [7-14]. Most of these studies are older and utilized much larger probes, making the procedure risky and less favorable. The purpose of this report is to present a case that a small 5 French IVUS probe was employed in a patient where vascular invasion could not be definitively diagnosed using noninvasive modalities after chemoradiation therapy.

\section{Case}

An 80 -year female with a past medical history significant for hypertension and pancreatitis presented with a one-month history of mild right upper quadrant aching pain, which radiated to her back. She denied any fever, weight loss, anorexia, emesis or changes in bowel habits. An abdominal ultrasound revealed cholelithiasis, a hypoechoic mass in the head of the pancreas and a dilated pancreatic duct. ERCP with biopsy confirmed pancreatic adenocarcinoma. Furthermore, the patient's CA $19-9$ was $43.3 \mathrm{U} / \mathrm{ml}$. A CT scan of the abdomen demonstrated the pancreatic mass abutting the superior mesenteric vein near its confluence with the splenic vein presumed to be a mass affect. A fat plane was questionable. No obvious vascular invasion was appreciated on CT and the patient was considered a surgical candidate. The patient did not want to proceed with surgery at that time, but chose chemoradiation treatment. After a short period of the therapy, she decided to proceed with surgical intervention. It was decided to reassess her stage of disease after she completed three rounds of chemotherapy utilizing gemcitabine and 5-Fluorouracil as well as external beam radiation. A 3 month follow-up CT scan was performed to restage the cancer. The mass had decreased in size; however, there was progressive involvement of the fat plane along the right lateral aspect of the wall of the confluence of jejunal branches as they become the SMV. Vascular involvement could not excluded by CT (Figure 1). The patient was scheduled for a percutaneous transhepatic intravascular ultrasound (IVUS) of the portal system to evaluate for tumor extension into the vessels in question.

The patient was taken to the angiography suite. Under ultrasound

*Corresponding author: Feghali A, Surgery Resident, State University of New York Upstate Medical University, 750 East Adams Street, Suite 8141, Syracuse, New York 13210, USA, Tel: 703-615-6508; E-mail: doctor.feghali@gmail.com

Received June 13, 2016; Accepted June 20, 2016; Published June 28, 2016

Citation: Feghali A, Amankwah K, Goldenberg A, Karmel M, Mendenhall C (2016) Utilization of Intravascular Ultrasound to Assess Vascular Invasion in Pancreatic Cancer Post Chemoradiation Therapy. J Vasc Med Surg 4: 275. doi:10.4172/23296925.1000275

Copyright: $\odot 2016$ Feghali A, et al. This is an open-access article distributed unde the terms of the Creative Commons Attribution License, which permits unrestricted use, distribution, and reproduction in any medium, provided the original author and source are credited. 


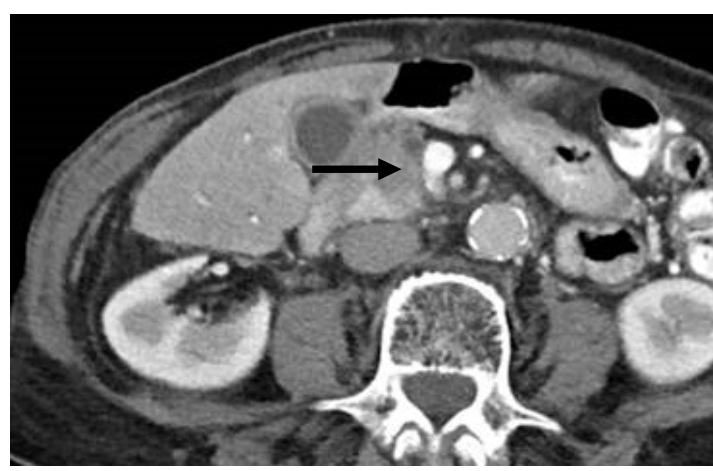

Figure 1: Questionable invasion of the SMV and jejunal branches status post chemo/radiation.

guidance, a 21-gauge AccuStick needle (Boston Scientific, Marlborough, Mass.) was introduced into a branch of the right portal vein, the needle stylet was removed and a portogram was performed to confirm position. With a 0.018 inch Nitinol guidewire a 6 French Pinnacle Destination Sheath (Terumo Medical Corp. Somerset, NJ) was placed. Using a 4 French angled Glidecath catheter (Terumo Medical Corp. Sumerset, NJ) inserted into the sheath, venography of the portal system was performed to delineate the superior mesenteric (SMV), jejunal venous branches and the splenic vein (Figure 2). Upon confirmation of the jejunal branch confluence with the superior mesenteric vein, the sheath was then advanced into the jejunal branch. With a 0.014 inch Command Guide Wire (Abbott Laboratories. Abbott Park, IL), a 5 French intravascular ultrasound (IVUS) probe (Eagle Eye, Volcano Corp. San Diego, CA.) was advanced over wire and through the sheath to the level of L5.

Ultrasound imaging was performed of the jejunal branch and the superior mesenteric vein. The probe was retracted at intervals of $0.5 \mathrm{~cm}$ and spot images were obtained with the IVUS and with fluoroscopy (Figures 3-5). Real time video of a pull-back ultrasonogram was also performed. As in previous studies, vascular invasion was considered positive when the echogenic wall of the vein was reduced to less than $0.5 \mathrm{~mm}$. There was complete obliteration of the echogenic wall of the jejunal branch in question seen on CT as it converged with the SMV. The surgeons at our institution required at least a $0.5 \mathrm{~cm}$ distal cuff of healthy SMV wall to anastomose with the proximal SMV or portal vein. Due to the findings using IVUS the patient was not considered a surgical candidate.

The procedure was terminated when it was determined the patient was not resectable. The IVUS was removed and a mixture of $1 \mathrm{~g}$ Avitene collagen powder (Bard inc. Murray Hill, NJ), $3 \mathrm{ml}$ normal saline and 3 $\mathrm{ml}$ iodinated contrast was backloaded into a $3 \mathrm{ml}$ syringe. The syringe was attached to the sheath dilator. The intrahepatic tract was embolized while withdrawing the sheath.

\section{Discussion}

Surgical resection continues to be the only potentially curative treatment for pancreatic cancer [15]. Often, the key determinant is the level and type of vascular involvement. Evaluation of the tumor and the involvement of the these vessels is critical in determining respectability [16]. Even after thorough assessment only $15-20 \%$ of patients are considered candidates for surgery. Many of these patients may be found to have microscopic margins at the time of surgery [17].
Furthermore, the most common surgical treatment for pancreatic head or body resection in the setting of pancreatic adenocarcinoma is the Whipple procedure, which has a $18-25 \% 5$ year survival rate.

The diagnosis of vascular invasion can be problematic. There is no consensus on optimal pre operative imaging assessment of vascular infiltration in patients with pancreatic cancer $[3,6,18,19]$. Vascular involvement has been reported between $21-64 \%$ depending on the population investigated $[5,20]$.

Computed tomography remains the initial modality when evaluating pancreatic cancer; however, other imaging modalities (MRI, PET, endoscopic ultrasound) have provided alternative methods to further assess this form of cancer [21-27]. Intravascular ultrasound has seen tremendous use in coronary and endovascular interventions. Several studies have expanded its utilization in the area of hepatobiliary disease $[10,13,14]$. An early pioneer of IVUS, Kaneko et al. [28] demonstrated IVUS could detect intraportal thrombus and invasion that was missed by CT. The group has used IVUS in the staging of pancreatic cancer and development of 3D reconstructions using the imaging modality [4]. These early reports used IVUS by trans

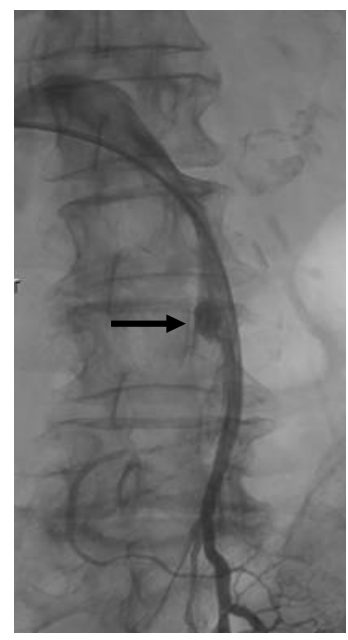

Figure 2: Angiography of jejunal venous branches, the SMV and portal veins via percutaneous access.

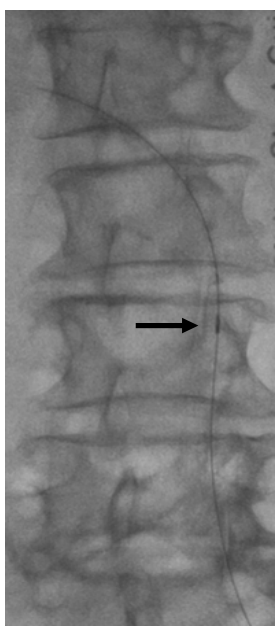

Figure 3: Tip of IVUS at confluence of jejunal branches and SMV. 
Citation: Feghali A, Amankwah K, Goldenberg A, Karmel M, Mendenhall C (2016) Utilization of Intravascular Ultrasound to Assess Vascular Invasion in Pancreatic Cancer Post Chemoradiation Therapy. J Vasc Med Surg 4: 275. doi:10.4172/2329-6925.1000275

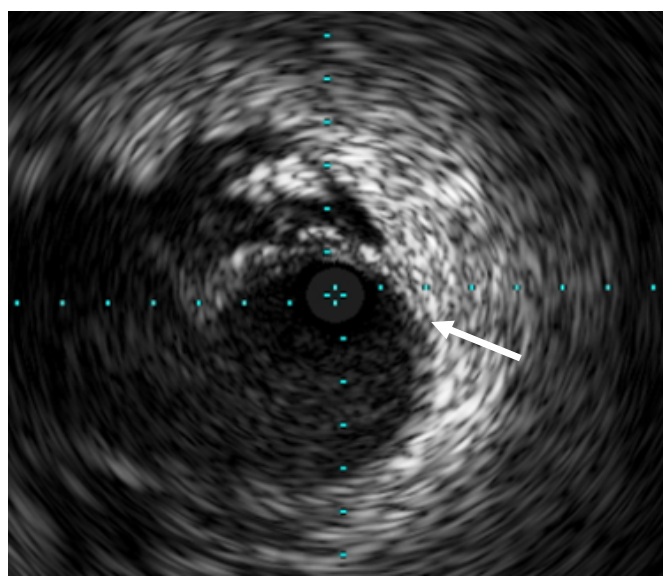

Figure 4: Intact wall of jejunal venous branches.

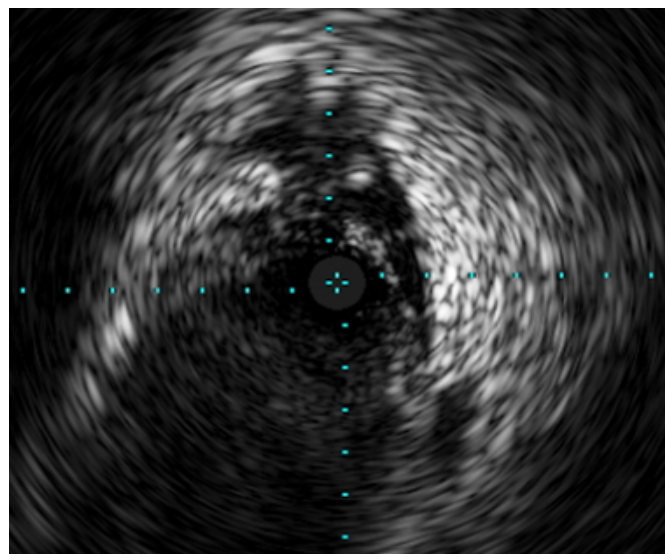

Figure 5: Wall invasion at confluence of jejunal branches and SMV.

mesenteric catheterization route. Further technique advancements allow it to be done percutanenously through transhepatic $[12,13]$ and trans femoral access [14].

Several reports have developed criteria for vascular invasion, which include loss of the echoic band of the portal hypoechoic tumor, the tumor mass blended with venous wall and tumour extension into the vascular lumen $[9-12,28]$. The specificity and sensitivity of this modality is greater than $95 \%$ and $90 \%$, respectively $[8,28]$. It has been reported that the limitations of IVUS are the examination of only the SMV and portal vein without arterial evaluation; however, one study performed a feasibility study of intra-arterial ultrasound in patients with pancreatic cancer. They found the information about the arterial involvement more detailed and the trans-femoral vessel approach easier than the transhepatic approach [14]. In either case, the IVUS probe should be placed into the vessel in question as the ability to resolve detail becomes equivalent to $\mathrm{CT}$ at $1 \mathrm{~cm}$ or greater.

IVUS continues to validate its utility as an adjunct in the evaluation of vascular invasion in pancreatic cancer, and the modern smaller probe sizes have been shown to be safe, effective and with a resolution superior to CT. Either venous or arterial lumens can be assessed. This case represents a first report of a 5 French IVUS probe being used post chemoradiation therapy to determine a patient's candidacy for resection. This form of imaging should be considered when other imaging modalities continue to provide equivocal results concerning vascular involvement.

\section{References}

1. Buchs NC, Chilcott M, Poletti PA (2010) Vascular invasion in pancreatic cancer: Imaging modalities, preoperative diagnosis and surgical management. World J Gastroenterol 16: 818-831.

2. Evans DB, Lee JE, Pisters PW, Charnsangavej C, Ellis LM, et al. (1997) Advances in the diagnosis and treatment of adenocarcinoma of the pancreas. Cancer Treat Res 90: 109-125.

3. Scaglione M, Pinto A, Romano S, Scialpi M, Volterrani L, et al. (2005) Using multidetector row computed tomography to diagnose and stage pancreatic carcinoma: the problems and the possibilities. JOP 6: 1-5.

4. Kaneko T, Inoue S, Sugimoto H, Takeda S, Harada A, et al (2001) Intraoperative diagnosis of pancreatic cancer extension using IVUS. Hepatogastroenterology 48: 944-948.

5. Megibow AJ, Zhou XH, Rotterdam H, Francis IR, Zerhouni EA, et al. (1995) Pancreatic adenocarcinoma: CT versus MR imaging in the evaluation of resectability--report of the Radiology Diagnostic Oncology Group. Radiology 195: 327-332.

6. Soriano A, Castells A, Ayuso C, Ayuso JR, de Caralt MT, et al. (2004) Preoperative staging and tumor resectability assessment of pancreatic cancer: prospective study comparing endoscopic ultrasonography, helica computed tomography, magnetic resonance imaging, and angiography. Am J Gastroenterol 99: 492-501.

7. Kaneko T, Nakao A, Harada A (1994) Intraportal endovascular ultrasonography in pancreatic cancer--a new technique for the diagnosis of portal vein invasion: a preliminary report. Surgery $115: 438-444$.

8. Kaneko T, Nakao A, Inoue S, Endo T, Itoh S, et al. (1994) Portal venous invasion by pancreatobiliary carcinoma: diagnosis with intraportal endovascular US. Radiology 192: 681-686.

9. Kaneko T, Nakao A, Takagi H (1998) Intraportal endovascular ultrasonography for pancreatic cancer. Semin Surg Oncol 15: 47-51.

10. Nakao A, Kaneko T (1999) Intravascular ultrasonography for assessment of portal vein invasion by pancreatic carcinoma. World J Surg 23: 892-895.

11. Hannesson PH, Stridbeck H, Lundstedt C (1997) Intravascular ultrasound for evaluation of portal venous involvement in pancreatic cancer. Eur Radiol 7 : $21-25$

12. Hannesson PH, Lundstedt C, Dawiskiba S (2002) Transhepatic intravascular ultrasound for evaluation of portal venous involvement in patients with cancer of the pancreatic head region. Eur Radiol 12: 1150-1154.

13. Stein M, Schneider PD, Ho HS (2002) Percutaneous transhepatic portography with intravascular ultrasonography for evaluation of venous involvement of hepatobiliary and pancreatic tumors. Journal of vascular and interventional radiology 13: 805-814

14. Larena-Avellaneda A, Timm S, Kickuth R (2010) Intraarterial ultrasound in pancreatic cancer: feasibility study and preliminary results. Cardiovasc Intervent Radiol 33: 726-731.

15. Ryan DP, Hong TS, Bardeesy N (2014) Pancreatic adenocarcinoma. N Engl J Med 371: 1039-1049.

16. Vauthey JN, Dixon E (2009) AHPBA/SSO/SSAT Consensus Conference on Resectable and Borderline Resectable Pancreatic Cancer: rationale and overview of the conference. Ann Surg Oncol 16: 1725-1726.

17. Konstantinidis IT, Warshaw AL, Allen JN (2013) Pancreatic ducta adenocarcinoma: is there a survival difference for $\mathrm{R} 1$ resections versus locally advanced unresectable tumors? What is a "true" R0 resection? Ann Surg 257 731-736.

18. Edge SB, Compton CC (2010) The American Joint Committee on Cancer: the 7th edition of the AJCC cancer staging manual and the future of TNM. Ann Surg Oncol 17: 1471-1474.

19. DeWitt J, Devereaux B, Chriswell M, McGreevy K, Howard T, et al. (2004) Comparison of endoscopic ultrasonography and multidetector computed tomography for detecting and staging pancreatic cancer. Ann Intern Med 141: 753-763. 
Citation: Feghali A, Amankwah K, Goldenberg A, Karmel M, Mendenhall C (2016) Utilization of Intravascular Ultrasound to Assess Vascular Invasion in Pancreatic Cancer Post Chemoradiation Therapy. J Vasc Med Surg 4: 275. doi:10.4172/2329-6925.1000275

20. Arslan A, Buanes T, Geitung JT (2001) Pancreatic carcinoma: MR, MR angiography and dynamic helical CT in the evaluation of vascular invasion. Eur J Radiol 38: 151-159.

21. Rösch T, Dittler HJ, Strobel K, Meining A, Schusdziarra V, et al. (2000) Endoscopic ultrasound criteria for vascular invasion in the staging of cancer of the head of the pancreas: a blind reevaluation of videotapes. Gastrointest Endosc 52: 469-477.

22. Saldinger PF, Reilly M, Reynolds K, Raptopoulos V, Chuttani R, et al. (2000) Is CT angiography sufficient for prediction of resectability of periampullary neoplasms? J Gastrointest Surg 4: 233-237.

23. Catalano C, Laghi A, Fraioli F, Pediconi F, Napoli A, et al. (2003) Pancreatic carcinoma: the role of high-resolution multislice spiral CT in the diagnosis and assessment of resectability. Eur Radiol 13: 149-156.

24. Bipat S, Phoa SS, van Delden OM (2005) Ultrasonography, computed tomography and magnetic resonance imaging for diagnosis and determining resectability of pancreatic adenocarcinoma: a meta-analysis. J Comput Assist Tomogr 29: 438-445.

25. Aslanian H, Salem R, Lee J, Andersen D, Robert M, et al. (2005) EUS diagnosis of vascular invasion in pancreatic cancer: surgical and histologic correlates. Am J Gastroenterol 100: 1381-1385.

26. Schwarz M, Pauls S, Sokiranski R (2001) Is a preoperative multidiagnostic approach to predict surgical resectability of periampullary tumors still effective? American journal of surgery 182: 243.

27. Delbeke D1, Pinson CW (2004) Pancreatic tumors: role of imaging in the diagnosis, staging, and treatment. J Hepatobiliary Pancreat Surg 11: 4-10.

28. Kaneko T1, Nakao A, Inoue S, Harada A, Nonami T, et al. (1995) Intraportal endovascular ultrasonography in the diagnosis of portal vein invasion by pancreatobiliary carcinoma. Ann Surg 222: 711-718. 